\title{
What can we tell about monetary policy synchronization and interdependence over the 2007-2009 global financial crisis?
}

\author{
Mohamed El Hedi Arouri \\ LEO, Universitéd'Orléans and EDHEC Business School, mohamed.arouri@univ-orleans.fr \\ Rue de Blois - BP 6739, 45067 Orléans cedex 2, France \\ Phone: +33238492410-Fax: +33238417380 \\ Fredj Jawadi* \\ Amiens School of Management and EconomiX-CNRS, fredj.jawadi@supco-amiens.fr \\ 18, place Saint Michel, 80000 Amiens, France \\ Phone: +33 322822441 \\ ${ }^{*}$ Corresponding author \\ Duc Khuong Nguyen \\ ISC Paris School of Management, France,dnguyen@groupeisc.com \\ 22, Boulevard du Fort de Vaux, 75017 Paris, France \\ Phone: +33140539999-Fax: +33140539898
}

\begin{abstract}
We investigate the synchronization and nonlinear adjustment dynamics of short-term interest rates for France, the UK and the US using the bi-directional feedback measures proposed by Geweke (1982) and appropriate smooth transition error-correction models (STECM). We find strong evidence of continual increases in bilateral synchronization of these rates from 2005 to 2009 as well as of their lead-lag causal interactions with a slight dominance of the US rate. Our results also indicate that short-term interest rates converge towards a common long-run equilibrium in a nonlinear manner and their time dynamics exhibit regime-switching behavior.
\end{abstract}

Keywords: interdependencies among short-term interest rates, feedback measure and STECM.

JEL classifications: C52, E40, E52, G01 


\section{Introduction}

It is now common that financial stability constitutes a key factor for a healthy and successful economy since in such context depositors and investors have confidence that the financial system is safe and stable with a high degree of resilience to internal and external shocks. Further, failures in particular areas cannot spread to other sectors or to the whole economy. Today, preserving financial stability is widely viewed as a primary role of central banks ${ }^{1}$. The underlying rationale for acting in accordance with this objective is that monetary policy and the stability of financial systems are closely interlinked. One should note that a large number of previous studies have found changes in target interest rates have had a significant impact on financial market conditions and stability, by affecting equity prices and macroeconomic fundamentals such as inflation and exchange rate equilibriums (see, Rigobon and Sack, 2003; Bernanke and Kuttner, 2005; Chen, 2007; Ioannidis and Kontonikas, 2007). To the extent that the financial system performs the function of efficiently allocating available funds to the most productive investments for individuals and corporations, the rise of financial instability can lead to stock market collapses and, as a result, provoke harmful repercussions on financial sector performance and economic growth as a whole. In this scheme of things, if central banks fail to control the growing financial instability, their policies may not be properly applied due to ineffective responses from financial markets and a pervasive lack of confidence by investors.

The role of central banks in the regulation of global financial stability has been however under close scrutiny in the aftermath of the financial crisis that originated with the massive failures of the subprime mortgage markets in the US and quickly spilled over to other countries. Besides the efforts of other authorities such as governments and international regulatory institutions, it is generally believed that policy interventions by central banks are essential to regulate financial 
stability and to reduce the negative impact of the financial crisis. But, how can these actions be made most effectively? To this extent, the majority of researchers and policymakers share a common view that more central bank coordination would help the global economy to recover from the financial crisis and we believe that there are at least three factors underpinning their coordinated actions.

First, policy coordination can help to remedy an operational asymmetry: that is, the current financial crisis is a global matter as a result of financial liberalization and globalization of capital markets, while policy coordination of central banks at international level appears to be visibly weak. During the recent fifth central banking conference of the European Central Bank (ECB), the Chairman of the US Federal Reserve System (US Fed), Ben Bernanke, pointed out that although the merits of coordinated monetary policies among central banks have been discussed and approved for decades, such coordination has been quite rare in practice. The unique example over the last years concerns the joint announcement of interest rate cuts by the US Fed with five other leading central banks on October 8, 2008, in an effort to calm down the financial market turmoil and to combat the significant deterioration of the main economic performance indicators (see, Table 1). Second, the recent episode of financial instability and crisis indicates that the hypothesis of efficient capital markets, the purpose of self-regulated markets and the resilience of free markets appear implausible. More market discipline, developed in a coordinated framework by central banks, thus seems necessary to deal with global economic challenges. Finally, as noted by many economists and banking experts, the current architecture of the global financial system is subject to much criticism due to the significant deficiencies and illegal actions carried out by major international financial institutions. That is, during the global financial crisis of 2007-2009, the International Monetary Fund appeared to demonstrate major failures in fostering 
global monetary cooperation and securing global financial stability, while the Bank of International Settlement failed to provide a prudential framework for macroeconomic policies. With the principal aim of restoring investor confidence and reducing the crisis impact on the real economy, and on financial and banking sectors, the central banks have been emerging as key actors in global regulation tasks by actively assuming their role as liquidity providers of last resort for the financial markets. They are however aware of the difficulties in global crisis monitoring without effective coordination with other central banks elsewhere.

\section{[Please insert Table 1]}

The context of today's global financial crisis and economic meltdown has created a natural framework for investigating the issue of central bank policy coordination. In this paper, we propose to draw inferences about the synchronization and interdependence of monetary policies conducted by leading central banks by analyzing short-term interest rate adjustment dynamics for France, the UK and the US over the recent periods, to the extent that changes in policy rates are reasonably reflected in short-term rates as soon as they are announced. The study is thus of paramount important for understanding the way each central bank conducts its monetary policy with its peers. For instance, the timelines of successive policy-rate changes presented in Table 1 witness some degree of policy synchronization and interdependence among of the three central banks under consideration ${ }^{2}$. Note however that we are not concerned by the timing of successive policy-rate changes and the probability that a central bank changes its target rate given a modification of another bank's policy rate, even though these issues are also of great interest to investors and policymakers (Scotti, 2006; Douglas and Kolar, 2009).

In the empirical part of the paper, we first examine whether the time variation of short-term interest rates of France, the UK and the US is synchronous over the study period. We directly 
infer the synchronization dynamics of these rates from estimating the Geweke (1982)'s feedback measures which can be seen ultimately as a cardinal indicator of the degree of monetary market comovement. We then investigate the linkages and adjustment process of the short-term interest rates, led by innovations in target rates announced by central banks, using in particular nonlinear univariate and trivariate cointegration techniques based on vector error-correction model (VECM) and smooth transition error-correction model (STECM). The proposed framework is advantageous in that it enables to capture the dynamic interdependence among nonstationary interest rate series. In particular, the regime-switching behavior in the nonlinear adjustment process of interest rates to their long-run equilibrium is also allowed by explicitly specifying a transition function with respect to a certain threshold. In theory, modeling nonlinearities in the interest rate dynamics is mainly motivated by heterogeneous transaction costs in international markets, nonlinear shock transmissions, and structural break behavior of interest rates (see, e.g., Anderson, 1997; Liu, 2001; Favero and Giavazzi, 2002)³.

Overall, the test of policy synchronization reveals a high percentage of contemporaneous association (feedback) among the 3-month interbank offered interest rates of respective countries over the period 2005-2010. We also find significant evidence of causal interactions among these rates with a dominant effect from the US to the remaining markets. It is finally shown that shortterm interest rates converge towards a common long-run equilibrium and their adjustment process is typically nonlinear and subject to regime shifts. These findings, consistent with those reported in Scotti (2006) for the US Fed and ECB pair, may be suggestive of the fact that the European, UK and US central banks have recently adopted similar policies. However, our results are more insightful as they provide some evidence of nonlinear, time-varying and threshold adjustment behavior of various interest rates. 
We present, in Section 2, our econometric approach and show how it is applied to reproduce the interest rate dynamics. Section 3 describes the data used and discusses the main empirical results. Section 4 concludes the paper.

\section{Econometric Methodology}

This section presents our econometric modeling approach to explore the synchronization and interdependencies among the short-term interest rates. We begin with a test of synchronization, and then show the ways we investigate the dynamic adjustment process of interest rates toward their long-run equilibrium.

\subsection{A test of interest rate synchronization}

We investigate the degree of synchronization among three short-term interest rate series by employing the statistical feedback measures, developed by Geweke (1982). This approach is of particular interest to our research question as it permits to disentangle both the direction and magnitude of linear relationships between two time series, while controlling for their contemporaneous association. The application of Geweke's feedback measures thus allows us to compare our results with those of Scotti (2006) who addresses the issue of monetary policy synchronization between the US Fed and the ECB by means of two econometric models, namely the Autoregressive Conditional Hazard, and the Conditional Ordered Probit ${ }^{4}$.

To implement the Geweke method, we first assume that the changes in the short-term interest rate in a given country can be modeled as a function of its own past values and of those of the lagged values in other countries, such as 


$$
\begin{aligned}
& \Delta Y_{t}^{U S}=a_{0}+\sum_{k=1}^{M_{1}} A_{k} \Delta Y_{t-k}^{U S}+\sum_{k=1}^{M_{2}} B_{k} \Delta Y_{t-k}^{U K}+\sum_{k=1}^{M_{3}} C_{k} \Delta Y_{t-k}^{F}+\varepsilon_{t}^{U S} \\
& \Delta Y_{t}^{U K}=b_{0}+\sum_{k=1}^{M_{1}} D_{k} \Delta Y_{t-k}^{U K}+\sum_{k=1}^{M_{2}} E_{k} \Delta Y_{t-k}^{U S}+\sum_{k=1}^{M_{3}} F_{k} \Delta Y_{t-k}^{F}+\varepsilon_{t}^{U K} \\
& \Delta Y_{t}^{F}=c_{0}+\sum_{k=1}^{M_{1}} G_{k} \Delta Y_{t-k}^{F}+\sum_{k=1}^{M_{2}} H_{k} \Delta Y_{t-k}^{U S}+\sum_{k=1}^{M_{3}} I_{k} \Delta Y_{t-k}^{U K}+\varepsilon_{t}^{F}
\end{aligned}
$$

where $\Delta Y_{t}^{U S}, \Delta Y_{t}^{U K}$, and $\Delta Y_{t}^{F}$ denote the daily changes in the short-term interest rates of the US, the UK and France respectively. The system residuals, $\varepsilon_{t}^{U S}, \varepsilon_{t}^{U K}$, and $\varepsilon_{t}^{F}$, are assumed to be identical and independently distributed with zero means and variances of $\sigma_{U S, t}^{2}, \sigma_{U K, t}^{2}$, and $\sigma_{F, t}^{2}$ respectively. They are further assumed to be not correlated serially, but may be contemporaneously correlated with each other. Building on the fact that the transmission of shocks to interest rates would be rapid when synchronous feedbacks exist, we intentionally set $M_{1}$ to be equal to ten business days, and $M_{2}$ and $M_{3}$ equal to five business days ${ }^{5}$. Accordingly, the estimates of the system's coefficient measure the degree to which interest rate in a particular country is allowed to be contemporaneously associated with, or lead/lag that in other markets of the system. For example, the coefficients, $H_{k}$ and $I_{k}$, reflect how the US and UK interest rates lead the French one across days. The contemporaneous correlations of the system residuals capture the relationship on the same business day.

As we would like to have an idea about the degree to which policy decisions of the studied central banks are synchronous, we test the null hypothesis that there exists no contemporaneous relationship between the three interest rate series. Under the null hypothesis, the system of equations from (1) to (3) is reduced to 


$$
\begin{aligned}
& \Delta Y_{t}^{U S}=a_{0}^{\prime}+\sum_{k=1}^{M_{1}} A_{k}^{\prime} \Delta Y_{t-k}^{U S}+\mu_{t}^{U S} \\
& \Delta Y_{t}^{U K}=b_{0}^{\prime}+\sum_{k=1}^{M_{1}} D_{k}^{\prime} \Delta Y_{t-k}^{U K}+\mu_{t}^{U K} \\
& \Delta Y_{t}^{F}=c_{0}^{\prime}+\sum_{k=1}^{M_{1}} G_{k}^{\prime} \Delta Y_{t-k}^{F}+\mu_{t}^{F}
\end{aligned}
$$

The system of restricted equations from (1) to (3) is estimated using seemingly unrelated regression (SUR) method while the system of unrestricted equations from (4) to (6) is estimated using OLS method. Once the estimation is done, we can perform the likelihood ratio test based on the estimated residual variances and covariances of the restricted and unrestricted equations. Note that these likelihood ratio test statistics correspond to the Geweke (1982)'s contemporaneous feedback measures (GCFM). For a given pair of countries $i$ and $j(i \neq j)$, they are computed as

$$
\operatorname{GCFM}_{i, j}=(N) \ln \left(\frac{\sigma_{\mu_{i}}^{2} \times \sigma_{\mu_{j}}^{2}}{|\Psi|}\right)
$$

In this formula, $\sigma_{\mu_{i}}^{2}$ and $\sigma_{\mu_{j}}^{2}$ are the estimated variances of the residuals for countries $i$ and $j$ from Equation (4) to Equation (6). $|\Psi|$ refers to the determinant of the covariance matrix of the estimated residuals from Equation (1) to Equation (3). $N$ is the sample size. Under the null hypothesis, $G C F M_{i, j}$ follows a $\chi^{2}(1)$. An increase (decrease) in a Geweke measure, from a year-toyear basis, indicates an increase (decrease) of the interest rate synchronization for a pair of countries. 


\subsection{Threshold cointegration modeling approach}

i) Basic linear adjustment

We first use the linear cointegration framework (Granger, 1981; Engle and Granger, 1987; Johansen, 1988) to investigate the long-run relationship between two integrated series of order one, $I(1)$, which is the case of short-term interest rates in this study. If two interest rate series, $X_{t}$ and $Y_{t}$, are cointegrated, a linear combination between them should be stationary, and there exists a long-run equilibrium to which the system converges over time, such as:

$$
Y_{t}=\alpha_{0}+\alpha_{1} X_{t}+z_{t}
$$

where $z_{t}$ corresponds to the equilibrium error indicating the deviation of the system of interest rates from their equilibrium at any point in time. $\left(\alpha_{0}, \alpha_{1}\right)$ defines the cointegrated vector. Under

the hypothesis of stationarity of $z_{t}$, the interest rate adjustment may be modeled using a standard linear error-correction model (LECM) as

$$
\Delta Y_{t}=\phi_{0}+\lambda z_{t-1}+\sum_{i=1}^{p} \phi_{1, i} \Delta Y_{t-i}+\sum_{i=1}^{p} \phi_{2, i} \Delta X_{t-i}+\varepsilon_{t}
$$

where $\lambda$ is the linear adjustment term ensuring the mean-reversion process to the equilibrium, $\phi_{1, i}$ and $\phi_{2, j}$ are autoregressive parameters with $\forall i=1, \ldots, p, \varepsilon_{t}$ is an error-term and $\varepsilon_{t} \rightarrow N\left(0, \sigma_{\varepsilon}^{2}\right)$.

This specification becomes however inefficient whenever the adjustment process is asymmetric, nonlinear with a time-varying adjustment speed. Thus, nonlinear adjustment models appear to be more appropriate for apprehending the said stylized facets. 
ii) STECM for nonlinear adjustment dynamics of interest rates

By introducing nonlinearity and regime-switching behavior into the LECM discussed above, Granger and Teräsvirta (1993) develop the class of STECMs ${ }^{6}$. This specification enables, on the one hand, the adjustment of interest rate dynamics to be smooth, nonlinear, and asymmetric with a time-varying adjustment speed. On the other hand, it models the dynamic adjustment process conditional on both the magnitude and/or the sign of disequilibrium associated with exogenous shocks affecting the system. Interestingly, recent studies which apply STECMs to economic data suggest their appropriateness in capturing nonlinearity, switching regimes, smoothness, and asymmetry in the adjustment dynamics induced by market frictions (Anderson, 1997; Escribano, 1997; Franses and Van Dijk, 2000; Liu, 2001; Jawadi et al., 2009).

Formally, a widely used two-regime STECM can be specified as a combination of two LECMs so that it incorporates two adjustment terms reproducing respectively the adjustment speed in the first regime and the intensity of error-correction in the second regime as follows

$$
\Delta Y_{t}=\phi_{0}+\lambda_{1} z_{t-1}+\sum_{i=1}^{p} \phi_{1, i} \Delta Y_{t-i}+\sum_{i=1}^{p} \phi_{2, i} \Delta X_{t-i}+\lambda_{2} z_{t-1} \times F\left(z_{t-d}, \gamma, c\right)+\varepsilon_{t}
$$

where $\lambda_{1}$ and $\lambda_{2}$ are the adjustment terms in the first and second regimes respectively; $z_{t-1}$ the error-correction term; $F($.) the transition function; $\gamma$ and $c$ the transition speed $(\gamma>0)$ and the threshold parameters respectively; $d$ the delay parameter; and $z_{t-d}$ the transition variable. Following Teräsvirta and Anderson (1992), $F($.$) is a nonlinear function bounded between 0$ and 1 and can be modeled by either a logistic function as

$$
F\left(z_{t-d}, \gamma, c\right)=\left[1+\exp \left(-\gamma\left(z_{t-d}-c\right)\right)\right]^{-1}
$$

or an exponential function as 


$$
F\left(z_{t-d}, \gamma, c\right)=1-\exp \left[-\gamma\left(z_{t-d}-c\right)^{2}\right]
$$

Then, the system of Equations (10) and (11) defines a logistic STECM (LSTECM), while the system of Equations (10) and (12) specifies an exponential STECM (ESTECM). The ESTECM captures the asymmetry in the size of interest rate deviations whereas the LSTECM reproduces the asymmetry in the sign of interest rate deviations. Overall, these models identify two different regimes for interest rate adjustment. In the first regime, interest rate deviations are small, and may be away from the equilibrium, uncorrected, and near unit root. The adjustment dynamics in this regime corresponds to

$$
\Delta Y_{t}=\phi_{0}+\lambda_{1} z_{t-1}+\sum_{i=1}^{p} \phi_{1, i} \Delta Y_{t-i}+\sum_{i=1}^{p} \phi_{2, i} \Delta X_{t-i}+\varepsilon_{t}
$$

The second regime is characterized by large interest rates being nonlinearly mean-reverting to equilibrium particularly when their deviations exceed some threshold. It is given by

$$
\Delta Y_{t}=\phi_{0}+\left(\lambda_{1}+\lambda_{2}\right) z_{t-1}+\sum_{i=1}^{p} \phi_{1, i} \Delta Y_{t-i}+\sum_{i=1}^{p} \phi_{2, i} \Delta X_{t-i}+\varepsilon_{t}
$$

Whatsoever the models, $\lambda_{1}$ and $\lambda_{2}$ are the most important parameters as their values and signs constrain the adjustment dynamics and the convergence speed of interest rates toward equilibrium (Michael et al., 1997). Even though $\lambda_{1}$ is positive, interest rates are nonlinearly meanreverting and the STECM is stable only if $\lambda_{2}$ and $\left(\lambda_{1}+\lambda_{2}\right)$ are negative and statistically significant. That is, for small deviations, interest rate movements may depart from the long-run equilibrium and would be characterized by explosive behavior or a unit root, while for large deviations, the adjustment process would be mean-reverting. 
Before the STECM can be estimated by the nonlinear least squares (NLS) method, we have to determine the optimal lag number, perform nonlinearity tests and choose the appropriate transition function (see, Van Dijk et al., 2002). More specifically, the optimal lag number $p$ is determined within the LECM based on usual information criteria (AIC and BIC), the Ljung-Box test for serial autocorrelation, and the partial autocorrelation function. A grid search is then conducted to define the possible value for the delay parameter, $d$. The plausible values that we consider for $d$ include the following set $[1,2,3,4,5]$ when using daily data. We finally apply nonlinear adjustment tests for the possible values of $d$, and the optimal value being used in the transition function of Equation (10) is the one for which linearity is most rejected.

As for the nonlinear adjustment tests, we are concerned by testing the null hypothesis of linearity $\mathrm{H}_{0}$ against its alternative of nonlinearity $\mathrm{H}_{1}$. Under $\mathrm{H}_{0}$, the interest rate adjustment dynamic is better reproduced by a LECM, while a STECM is more appropriate under $\left(\mathrm{H}_{1}\right)$. We employ the Lagrange Multiplier (LM) statistics of the $\mathrm{LM}_{3}$ test, as suggested by Luukkonen et al. (1988), to make decisions between linear and nonlinear specifications ${ }^{7}$. It is important to note that the LM tests permit to avoid the nuisance parameter problem, and their distribution is known under $\mathrm{H}_{0}$ and follows a standard $\chi^{2}$ distribution. As stated above, the $\mathrm{LM}_{3}$ statistics are computed for all possible values of $d$.

\section{Data and Empirical Results}

\subsection{Data and preliminary results}

This paper uses the daily three-month interbank offered interest rates from France, the UK and the US. The sample countries are selected because of the strategic role of their central banks in 
regulating international monetary markets over the recent crisis. In addition, the French rate is considered as a representative short-term interest rate for the Euro currency area since there is only little empirical evidence to support the dominant influence of one particular rate on the others (Uctum, 1999; Wang et al., 2007), while the French rate is found to play a dominant role in international monetary markets (Awad and Goodwin, 1998). The data are obtained from Datastream International and cover the period December 31, 2004 to March 30, 2010. Working with daily data is supported by the fact that monetary policy adjustments tend to be immediate in the short-term. We plot the time variations of raw data in Figure 1 and observe several important facts. At first, the French and UK rates do not follow the US rate before the mid-2008 marked by the severe impact of the global financial crisis, but they have somewhat the same behavior afterwards. Next, the time-paths of these rates are exposed to structural breaks and cyclical dynamics with several significant peaks. Finally, their comovement tends to be higher when we approach the end of the study period, which may indicate some evidence of interest-rate policy synchronization.

\section{[Please insert Figure 1]}

We then examine the stationary properties of the interest rate series considered using widely used unit root tests proposed by Dickey and Fuller (1981), Phillips and Perron (1988), and Zivot and Andrew (1992), with the latter being robust to structural breaks. The obtained results, not reported here to conserve spaces but available under request, indicate that the hypothesis of unit root cannot be rejected for all the series, meaning that they are integrated of order one.

We also compute the bilateral correlations among the short-term interest rates over two subperiods in order to get insights about their recent joint behavior and report the results in Table 2. As expected, the findings show a significant increase in bilateral correlations after the subprime cri- 
sis. This is potentially indicative of greater synchronization of monetary policy decisions by the US Fed, ECB and Bank of England (BoE) as they have been willing to coordinate more for global financial stability issues.

\section{[Please insert Tables 2 and 3]}

Descriptive statistics of short-term interest rates reported in Table 3 show that they all have negative average in recent periods due to their large decrease, notably after the advent of the subprime crisis. The significant rejection of normality, the negative sign of the skewness as well as the leptokurtic behavior of the interest rates suggest further nonlinearity in their dynamics. Moreover, the similar patterns found for all interest rates under consideration are somewhat an indication of their common trends resulting potentially from higher policy synchronization among the central banks.

\subsection{Short-term interest rate synchronization}

To test for the synchronization hypothesis, we compute the Geweke contemporaneous feedback measures (GCFM) for three pairs of interest rates for each year from 2005 to 2009. The results of the test are reported in Table 4. Overall, we find a high percentage of contemporaneous interdependence among the interest rates considered. Of the fifteen GCFM ratios, twelve are significant at the $1 \%$ level. The average levels of bilateral interdependences range from 50.84 (US-France) to 101.12 (US-UK). We further observe that there is no contemporaneous feedback between the US and UK rates in 2005 and 2006, and between the UK and French rates in 2005. More importantly, the amplitude of the linkages increases over time towards the end of the estimation period. It goes from 0.00 to 210.20 for US-UK pair, from 17.50 to 75.70 for US-France pair, and from 0.00 to 100.50 for UK-France pair. This can be explained, with reference to Table 1 , by the greater intensity of overlapping policy decisions, especially between the US and UK central 
banks. The ECB has, under the crisis pressure, derogated from its conventional objective aiming at keeping inflation rate lower than $2 \%$ and started to decrease its target rate in response to the similar interventions by other central banks.

\section{[Please insert Table 4]}

It seems from the above findings that shocks to short-term interest rates were contemporaneously transmitted internationally among the countries under consideration. This implies that each central bank may revise its target rate with a positive feedback to the others' policy decisions. Note however that the tendency of intensified comovement across short-term interest rates is on average higher for the US-UK pair than for the US-France and UK-France pairs. This is consistent with the results of Awad and Goodwin (1998) on the basis of a VAR impulseresponse analysis that shocks to the US real interest rate spark off more significant reactions from real interest rates in the UK and Canada. To further apprehend the feedback-policy rules among the three central banks, we study, in what follows, the dynamic interdependence of shortterm interest rates within both linear and nonlinear cointegration frameworks.

\subsection{Linear cointegration tests}

i) The Engle and Granger (1987)'s approach

We examine the hypothesis of long-run relationship between short-term interest rates by testing the stationarity of the residual series $z_{t}$, given by

$$
Y_{t}^{j}=\alpha+\beta Y_{t}^{k}+\delta Y_{t}^{l}+z_{t}
$$

where $Y_{t}$ denotes the short-term interest rate of country $j$ at time $t ;(\alpha, \beta, \delta)$ the cointegrated vector; and $z_{t}$ measures the disequilibrium error. We consider three cases as follows: $j, k$, and $l$ 
represent France, the US, and the UK; the UK, the USA and France; and the USA, France, and the UK respectively.

\section{[Please insert Table 5]}

The obtained results in Table 5 indicate that the null hypothesis of presence of a unit root is rejected at 5\% according to $\mathrm{ADF}$ test, leading us to conclude that the three interest rates are linearly cointegrated. To insure the robustness of the results, we use Zivot and Andrews (1992)'s test which allows for breaks in the trend and is thus more powerful for data generated potentially by nonlinear models. Accordingly, the linear cointegration hypothesis is not rejected for France and the UK. It thus means that the system of interest rates converges to a common equilibrium over the long-run, and their dynamics may be reproduced by a LECM.

ii) The Johansen (1988)'s cointegration test

We also investigate the cointegration hypothesis using the trace test of Johansen (1988) that offers the possibility to test simultaneously for several cointegration relationships. Specifically, the trace test checks the null hypothesis of "no cointegration relationship" against its alternative of at most one cointegration relationship. The test results, reported in Table 6 show that the null hypothesis is rejected at the $5 \%$ level suggesting the presence of at most one cointegration relationship. It is therefore clear that a LECM specified on the basis of the results from Engle and Granger (1987)'s cointegration test is not accurate.

\section{[Please insert Table 6]}

Then, we estimate a 3-equation VECM and report the results in Table 7 . We find that the linear adjustment term is significant at the $1 \%$ only for France, which might reflect the reaction of the ECB to the interest-rate cuts by the Fed and the Bank of England. Moreover, our results highlight substantial evidence of dynamic interactions among the sample interest rates as changes in 
each country's short-term interest rate depend not only on their previous variations, but also on those of interest rates in other countries. For the UK and US, this cross-market interdependence appears to remain significant until the second business day, reflecting the existence of learning effects about temporal shock transmission between different countries. The different signs observed for autoregressive coefficients may reflect the different ways in which central banks manage the financial crisis via short-term interest rate instrument. For example, the Fed has undertaken successive cuts in its policy rate since September 18, 2007 just after the release of the subprime crisis, while the ECB kept its target rate constant, even increased it, and only decreased it in the late 2008 (Table 1).

\section{[Please insert Table 7]}

Summarizing all, our findings provide some evidence of significant linkages between shortterm interest rates, which typically suggests that a particular country's central bank does adjust its policy rate with respect to the changes in policy rates of the others. This linear modeling has, however, a major drawback as it supposes symmetric linkages among interest rates before and after the crisis, while monetary policy is not the same during these two periods. In addition, several previous studies have documented that imposing linearity and symmetry in interest rate modeling may be restrictive (Liu, 2001). Therefore, a nonlinear framework accommodating for both time-varying and regime-switching behavior in the adjustment process of interest rates is of particular interest since it permits to capture the asymmetry in their dynamic relationship across regimes (e.g., expansion and crisis regimes). Over the recent period marked by the recent global financial crisis, interest rate movements are likely to exhibit asymmetric and regime-switching dynamics, being neglected by linear models, see for example the LECM in Equation (9). One may note that the intensity of policy rate modifications is exceptionally higher during the sub- 
prime crisis than before. The significance of the skewness coefficients of interest-rate distributions is also suggestive of the potential asymmetry.

\subsection{Estimation results of the STECM for interest rate dynamics}

The STECM that we use to explore the adjustment dynamics of interest rate changes is represented by Equation (17) where we introduce into each short-term nonlinear ECM the lagged interest rate changes of the country under consideration, the lagged interest rate changes of the other countries.

$$
\Delta Y_{t}^{j}=\phi_{0}+\lambda_{1} z_{t-1}+\sum_{i=1}^{p} \phi_{1, i} \Delta Y_{t-i}^{j}+\sum_{i=1}^{p_{1}} \phi_{2, j} \Delta Y_{t-i}^{k}+\sum_{i=1}^{p_{2}} \phi_{3, l} \Delta Y_{t-i}^{l}+\lambda_{2} z_{t-1} \times F\left(z_{t-d}, \gamma, c\right)+\varepsilon_{t}
$$

where $Y_{t}$ represents the interest rate of the country $j$, and $z_{t}$ measures the disequilibrium error from the cointegration relationship. Three different cases are considered: for $j=$ France, $k=\mathrm{US}$, and $l=\mathrm{UK}$; for $j=\mathrm{UK}, k=\mathrm{US}$, and $l=$ France; and finally for $j=\mathrm{US}, k=$ France and $l=\mathrm{UK}$. As discussed in Section 2, this modeling approach allows us to apprehend how far one interest rate deviates following a change in the other interest rates, while enabling its adjustment dynamics to be nonlinearly time-varying and asymmetric with regime-switching.

\section{i) Specification}

We first determine the optimal lag length in the empirical model and we, select four lags $(p=4)$ for all interest rates considered, which a priori indicates some signs of persistence inherent to the interest rate adjustment dynamics. Nonlinear adjustment tests (Luukkonen et al. 1988) are then employed to check for nonlinearity, while Tersävirta's tests are applied to specify the type of transition functions for the STECM respectively. Main findings indicate that the linearity hypothesis is strongly rejected for all interest rates, and that the exponential function is suitable for governing the regime transition in their adjustment process (Table 8). 


\section{[Please insert Table 8]}

It should be noted that the rejection of linearity and the choice of an exponential transition function for all countries suggest some similarities in the behavior of the three interest rates. Moreover, the validation of the regime-switching hypothesis implies the existence of at least two types of regime in the interest rate adjustment dynamics, the "central regime of segmentation" and the "upper regime of integration (or synchronization)". The activation of these regimes and the transition from one regime to another depends on the intensity and magnitude of changes in short-term interest rate changes, conditionally on shifts in monetary policy rates.

ii) Estimation and validation

According to specification tests, the following specifications $\operatorname{ESTECM}(4,4), \operatorname{ESTECM}(4,4)$, and ESTECM $(4,1)$ are estimated for the US, the UK, and France respectively. Table 9 reports the estimation results, and several important facts can be noted. At first, we look at the statistical properties of residual series issued from our nonlinear models and find that they are symmetric, stationary, and not serially correlated. This suggests that the introduction of nonlinearity enables to improve the adjustment process for interest rates. Second, most of AR coefficients are positive and statistically significant, thus confirming the persistence effects suggested by linear modeling, and reflecting successive interest rate cuts by central banks since the emergence of the US subprime crisis.

Third, all interest rate series we consider are found to be significantly affected by previous changes in foreign interest rates. This indicates some evidence of interest rate interdependence, at least over the most recent months as shown in Figure 1. Further, the coefficients associated with lagged interest-rate variables become more significant than they are in the linear model, leading us to conclude that the interaction between interest rates occurs rather in an asymmetric 
and nonlinear manner. If short-term interest rates reasonably capture monetary policy decisions, these findings should imply different feedback regimes and significant lead-lag effects between the central banks under consideration. In other words, a change in policy rate by a central bank has significant effect on monetary policy of the others, which may persist until the whole information regarding this decision is fully extracted.

Fourth, the estimated parameters of the exponential function are statistically significant, which confirms the Teräsvirta (1994) test regarding the presence of nonlinearity and suggests the existence of two different regimes characterizing the dynamics of interest rate deviations. That is, a "central regime of segmentation" or central regime in which the interest rate may deviate from its long-run equilibrium established with other interest rates and be uncorrected until its deviations exceed a certain threshold, and an "upper regime of synchronization" or upper regime describing the dynamics of the interest rate when it moves back to equilibrium owing to the activation of the nonlinear adjustment terms $\hat{\lambda}_{1}$ and $\hat{\lambda}_{2}$. The latter, being the most important parameters of the nonlinear adjustment model, are all significant at conventional levels, except for $\hat{\lambda}_{1}$ in the UK. The negativity of the second adjustment term $\hat{\lambda}_{2}$ in all three cases as well as of the sum $\left(\hat{\lambda}_{1}+\hat{\lambda}_{2}\right)$ means that even though short-term interest rates may deviate from the equilibrium (i.e., $\hat{\lambda}_{1} \geq 0$ ) in the first regime, they are nonlinearly mean-reverting and the estimated ESTECM are stable over the estimation period. Interestingly, the fact that the values of the adjustment terms are in general very low and do not exceed $6 \%$ in all cases clearly reflects the persistence associated with the interest rate changes that may escape linear modeling. It is equally important to note that the transition between interest rate regimes is quite smooth in view of the low value of the transition speed variable. 


\section{[Please insert Table 9]}

Fifth, to better apprehend the different regimes characterizing the interest rate adjustment dynamics, we plot the estimated transition functions for the UK, the US and France together with either transition variable or the time factor in Figure 2. We observe, on the one hand, that the most observations are symmetrically distributed particularly for the USA, confirming the choice of the exponential representation. On the other hand, the estimated transition functions show the presence of time-varying adjustment speed that increases with the magnitude of the interest rate deviations, or equivalently the more important the interest rate deviations, the more rapid the mean-reversion process is. Interestingly, the estimated transition function values are very low and did not achieve the upper regimes. This leads us to think that interest rate interactions and synchronization among sample countries are still in progress. From a statistical view, it also reveals that interest rate deviations have a near unit-root behavior in the central regime, while their dynamics may approach a random walk to insure the mean-reversion in interest rates in the upper regime.

Finally, our findings suggest that the US interest rate is characterized by the most volatile transition function, perhaps because of the Fed's successive policy rate cuts. The close inspection of the graphs in Figure 2 shows similar dynamics of interest rate adjustment, especially at the end of the estimation period as they tend to persist in the central regime. This may suggest some evidence of central bank synchronization.

\section{[Please insert Figure 2]}

To sum up, our results provide significant evidence of nonlinear interdependence of shortterm interest rates for France, the UK and the US, as well as several similarities in their adjustment dynamics. Since short-term interest rates often serve as monetary policy instrument, central 
bankers may determine, based on our empirical framework, the interest rate threshold above which appropriate feedback actions should be undertaken.

\section{Concluding Remarks}

This paper examines the synchronization and interdependence of short-term interest rates for France, the UK and the US within the context of today's global financial crisis and economic meltdown. To the extent that central bankers have had to coordinate more to deal with the crisis issues and ultimately to make policy decisions on interest rates that would reduce financial instability and restore investors' confidence, our study may provide some guidelines for monetary policy feedback rules. To this end, we employ Geweke (1982)'s feedback measures to test for the synchronization hypothesis, and develop a threshold cointegration framework to investigate both short and long-run relationships between the variables of interest. The main advantage of the proposed econometric methodology is its suitability for capturing any forms of asymmetry, nonlinearity and structural changes in interest rate interdependence and adjustment dynamics.

Our findings are mainly consistent with the hypothesis of increased synchronization and strong nonlinear interactions between the three short-term interest rates we consider. In particular, we find that exogenous shifts in the US rate lead those in France and the UK within a horizon of one to two business days. Empirical results from nonlinear models also suggest that interest rates, through their mean-reverting adjustment properties, converge towards a common equilibrium, which can be interpreted as evidence of increasing policy synchronization. 


\section{References}

Anderson, Heather M. (1997). "Transaction Costs and Nonlinear Adjustment towards Equilibrium in the US Treasury Bill Market.” Oxford Bulletin of Economics and Statistics 59, 465484.

Awad, Mouawiya M., and Barry K. Goodwin. (1998) "Dynamic Linkages among Real Interest Rates in International Capital Markets.” Journal of International Money and Finance 17, 881907.

Balke, Nathan S., and Thomas B. Fomby. (1997) “Threshold Cointegration.” International Economic Review 38, 627-645.

Bernanke, Ben S., and Kenneth N. Kuttner. (2005) "What Explains the Stock Market's Reaction to Federal Reserve Policy.” Journal of Finance, 60, 1221-1257.

Chen, Shiu-Sheng. (2007) "Does Monetary Policy have Asymmetric Effects on Stock Returns?.” Journal of Money, Credit and Banking 39, 667-668.

Cihák, Martin. (2006), “How do Central Banks Write on Financial Stability?.” Working Paper No. 06/163, International Monetary Fund.

Dickey, David A., and Wayne A. Fuller. (1981) "Likelihood Ratio Statistics for Autoregressive Time Series with a Unit Root.” Econometrica 49, 1057-1072.

Douglas, Christopher C., and Marek Kolar. (2009) "Capturing the Time Dynamics of Central Bank Intervention.” Journal of International Financial Markets, Institutions and Money 19, 950968.

Engle, Robert F., and Clive W.J. Granger. (1987) "Cointegration and Error Correction: Representation, Estimation and Testing.” Econometrica 55, 251-276. 
Engle, Robert F., and Jeffrey R. Russell. (1998) “Autoregressive Conditional Duration: A New Model for Irregularly Spaced Transaction Data.” Econometrica 66, 1127-1162.

Escribano, Alvaro. (1997) "Nonlinear Error-Correction: The Case of Money Demand in the UK (1878-1970).” Working Paper No. 96-55, Universidad Carlos III De Madrid.

Eusepi, Stefano. (2010) “Central Bank Communication and the Liquidity Trap.” Journal of Money, Credit and Banking 42, 373-397.

Favero, Carlo A., and Francesco Giavazzi. (2002) "Is the International Propagation of Financial Shocks Nonlinear? Evidence from the ERM.” Journal of International Economics 57, 231-246.

Franses, Philip Hans, and Dick van Dijk. (2000) Non-linear time series models in empirical finance. Cambridge: Cambridge University Press.

Goodhart, Charles Albert Eric. (2006) “A Framework for Assessing Financial Stability?.” Journal of Banking and Finance 30, 3415-3422.

Granger, Clive W.J. (1981) "Cointegrating Variables and Error Correcting Models." Working Paper, University of California, San Diego.

Granger, Clive W.J., and Timo Teräsvirta. (1993) Modelling Nonlinear Economic Relationships. Oxford: Oxford University Press.

Hamilton, James D., and Oscar Jordà. (2002) “A Model for the Federal Reserve Rate Target." Journal of Political Economy 110, 1135-1167.

Healey, Juliette. (2001) “Financial Instability and the Central Bank - International Evidence.” In Financial Instability and Central Banks - A Global Perspective, edited by Richard Brealey, A. Clark, C. Goodhart, J. Healey, G. Hoggarth, D.T. Llewellyn, C. Shu, P. Sinclair and F. Soussa. London: Centre for Central Bank Studies, Bank of England). 
Ioannidis, Christos, and Alexandros Kontonikas. (2007) “The Impact of Monetary Policy on Stock Prices.” Journal of Policy Modeling 30, 33-53.

Jawadi, Fredj, and Georges Prat. (2009) "Nonlinear Stock Price Adjustment in the G7 Countries.” Working Paper, University of Paris Ouest La Defense Nanterre.

Jawadi, Fredj, Catherine Bruneau, and Nadia Sghaier. (2009) “Nonlinear Cointegration Relationships between Non-life Insurance Premium and Financial Markets." Journal of Risk and Insurance $76,753-783$.

Johansen, Soren. (1988) "Statistical Analysis of Cointegration Vectors." Journal of Economic Dynamics and Control 12, 231-254.

Liu, Ying. (2001) "Modelling Mortgage Rate Changes with a Smooth Transition Error Correction Model.” Working Paper No. 23, Bank of Canada.

Luukkonen, Ritva, and Pentti Saïkkonen. (1988) "Lagrange Multiplier Tests for Testing Nonlinearity in Time Series Models." Scandinavian Journal of Statistic 15, 65-68.

Luukkonen, Ritva, Pentti Saïkkonen, and Timo Teräsvirta. (1988) “Testing Linearity against Smooth Transition Autoregressive Models", Biometrika 75, 491-499.

Michael, Panos, Nobay, Robert A., and David A. Peel. (1997) "Transactions Costs and Nonlinear Adjustment in the Real Exchange Rates: an Empirical Investigation.”, Journal of Political Economy 105, 862-879.

Peel, David A., and Mark P. Taylor. (2000) "Nonlinear Adjustment, Long-run Equilibrium and Exchange Rates Fundamentals.” Journal of International Money and Finance 19, 33-53.

Phillips, Peter C.B., and Pierre Perron. (1988) "Testing for Unit Root in a Time Series Regression." Biometrika 75, 335-346. 
Rigobon, Roberto, and Brian Sack. (2003) "Measuring the Reaction of Monetary Policy to the Stock Market.” Quarterly Journal of Economics 118, 639-669.

Scotti, Chiara. (2006) “A Bivariate Model of Fed and ECB Main Policy Rates.” International Finance Discussions Paper, Board of Governors of the Federal Reserve System.

Teräsvirta, Timo. (1994) "Specification, Estimation and Evaluation of Smooth Transition Autoregressive Models." Journal of the American Statistical Association 89, 208-218.

Teräsvirta, Timo, and Heather M Anderson. (1992) "Characterizing Nonlinearities in Business Cycles using Smooth Transition Autoregressive Models.” Journal of Applied Econometrics 7, 119-136.

Uctum, Merih A. (1999) “European Integration and Asymmetry in the EMS." Journal of International Money and Finance 18, 769-798.

Van Dijk, Dick, Timo Teräsvirta, and Philip Hans Franses. (2002) "Smooth Transition Autoregressive Models - a Survey of Recent Developments." Econometric Reviews 21, 1-47.

Wang, Zijun, Jian Yang, and Qi Li. (2007) "Interest Rate Linkages in the Eurocurrency Market: Contemporaneous and Out-of-Sample Granger Causality Tests.” Journal of International Money and Finance 26, 86-103. 


\section{NOTES}

${ }^{1}$ The issue of financial stability and central bank missions has been examined by, among others, Healey (2001), Goodhart (2006) and Cihák (2006).

${ }^{2}$ It should be noted that in this paper the European Central Bank, being the central bank for Europe's single currency system, is the representative central bank for France.

${ }^{3}$ See Euspei (2010) for a nonlinear model of monetary policy and central bank behavior.

${ }^{4}$ These models enable to evaluate not only the timing and magnitude of policy changes, but also the probability that a central bank changes its policy rate at a given point in time conditionally on another one's policy decision. We refer to Scotti (2006) for a detailed discussion of their theoretical aspects and empirical applications. It is however worth noting that the $\mathrm{ACH}$ model, proposed by Hamilton and Jordà (2002), is an extension of the Autoregressive Conditional Duration model of Engle and Russell (1998).

${ }^{5}$ It is noted that adding values of $M_{1}$ and $M_{2}$, and of $M_{1}$ and $M_{3}$ beyond a ratio of 10/5 does not systematically change the significance of the observed Geweke feedback measures.

${ }^{6}$ See Van Dijk et al. (2002) for the statistical properties and modeling approach of these models.

${ }^{7}$ For concision purpose, the readers are invited to refer to Luukkonen et al. (1988) for the testing procedure for nonlinearity, and to Van Dijk et al. (2002) for more details about the LM tests. 
Table 1: Timelines of target interest rate changes by the US Fed, the Bank of England and the European Central Bank: Sep. 2007 - Mar. 2010

\begin{tabular}{|c|c|c|c|c|c|}
\hline \multicolumn{2}{|c|}{ US Federal Reserve System } & \multicolumn{2}{|c|}{ Bank of England } & \multicolumn{2}{|c|}{ European Central Bank } \\
\hline $\begin{array}{c}\text { Announcement } \\
\text { dates }\end{array}$ & $\begin{array}{c}\text { Magnitude of } \\
\text { change }\end{array}$ & $\begin{array}{c}\text { Announcement } \\
\text { dates }\end{array}$ & $\begin{array}{c}\text { Magnitude of } \\
\text { change }\end{array}$ & $\begin{array}{c}\text { Announcement } \\
\text { dates }\end{array}$ & $\begin{array}{l}\text { Magnitude } \\
\text { of change }\end{array}$ \\
\hline Sep. 18, 2007 & -50 & & & & \\
\hline Oct. 31,2007 & -25 & & & & \\
\hline Dec. 11,2007 & -25 & Dec. 6, 2007 & -25 & & \\
\hline Jan. 22, 2008 & -75 & Jan., 2008 & -25 & & \\
\hline Jan. 30, 2008 & -50 & & & & \\
\hline Mar. 18, 2008 & -75 & & & & \\
\hline Apr. 30, 2008 & -25 & Apr. 10, 2008 & -25 & & \\
\hline & & & & Jul. 9, 2008 & +25 \\
\hline Oct. 8,2008 & -50 & Oct. 8,2008 & -50 & Oct. 8,2008 & -50 \\
\hline Oct. 29,2008 & -50 & & & Oct. 9, 2008 & +50 \\
\hline & & Nov. 6, 2008 & -150 & Nov. 12, 2008 & -50 \\
\hline Dec. 16,2008 & -75 & Dec. 4,2008 & -100 & Dec. 10,2008 & -75 \\
\hline & & Jan. 8, 2009 & -50 & Jan. 21, 2009 & -100 \\
\hline & & Feb. 5, 2009 & -50 & & \\
\hline & & Mar. 5, 2009 & -50 & Mar. 11, 2009 & -50 \\
\hline & & & & Apr. 8, 2009 & -50 \\
\hline
\end{tabular}

Note: The target rate changes are expressed in basis points compared to the previous levels. For the US, the changes in federal funds rate (i.e., the interest rate at which depository institutions lend balances at the Federal Reserve to other depository institutions overnight) are specified and announced by the Federal Open Market Committee (FOMC) in its policy stance. For the UK, the official Bank Rate (i.e., interest rate paid on commercial bank reserves) is voted by the Bank of England's Monetary Policy Committee. The ECB key interest rate is set by its Governing Council and refers to its deposit rate published in the monthly bulletin. 
Table 2: Correlation matrix

\begin{tabular}{|c|c|c|c|c|c|c|c|}
\hline \multicolumn{4}{|c|}{ December 31, 2004 - July 31, 2007} & \multicolumn{4}{|c|}{ August 01, 2007-March 30, 2010} \\
\hline & DYF & DYUK & DYUS & & DYF & DYUK & DYUS \\
\hline DYF & 1.000 & 0.050 & 0.030 & DYF & 1.000 & 0.500 & 0.380 \\
\hline DYUK & & 1.000 & 0.009 & DYUK & & 1.000 & 0.300 \\
\hline DYUS & & & 1.000 & DYUS & & & 1.000 \\
\hline
\end{tabular}

Note: DYF, DYUS and DYUK denote interest rate changes for France, the US and the UK respectively. 
Table 3: Descriptive statistics for interest rate changes

\begin{tabular}{lrrr}
\hline & DYUS & DYUK & DYF \\
\hline Mean $\left(\times 10^{5}\right)$ & -1.66 & -3.10 & -1.11 \\
Standard deviation $\left(\left(\times 10^{2}\right)\right.$ & 0.03 & 0.03 & 0.01 \\
Skewness & -2.88 & -17.80 & -1.09 \\
Kurtosis & 46.37 & 503.60 & 14.78 \\
Jarque-Bera statistics & 109073.80 & 143485.78 & 8180.707 \\
(p-value) & $(0.00)$ & $(0.00)$ & $(0.00)$ \\
\hline
\end{tabular}


Table 4: Geweke contemporaneous feedback measures among short-term interest rates

\begin{tabular}{lrrr}
\hline Year & US*UK & US*FR & UK*FR \\
\hline 2005 & 0.00 & $17.50^{*}$ & 0.00 \\
2006 & 0.00 & $35.60^{*}$ & $25.10^{*}$ \\
2007 & $120.10^{*}$ & $70.20^{*}$ & $72.50^{*}$ \\
2008 & $175.30^{*}$ & $55.20^{*}$ & $95.20^{*}$ \\
2009 & $210.20^{*}$ & $75.70^{*}$ & $100.50^{*}$ \\
\hline Average & $101.12^{*}$ & $50.84^{*}$ & $58.66^{*}$ \\
\hline
\end{tabular}

Notes: ${ }^{*}$ denotes the rejection at the $1 \%$ level of the null hypothesis that there is no contemporaneous relationship between the interest rates of the US Fed, ECB and BoE. 
Table 5: Results of linear cointegration tests

\begin{tabular}{|l|r|r|r|}
\hline & France & UK & US \\
\hline$\alpha\left(\times 10^{3}\right)$ & 2.00 & 0.30 & 0.06 \\
& $(4.01)$ & $(8.20)$ & $(2.05)$ \\
\hline$\beta$ & -0.24 & 0.47 & -0.55 \\
& $(-14.50)$ & $(41.5)$ & $(-14.50)$ \\
\hline$\delta$ & 0.84 & 0.79 & 1.17 \\
& $(52.60)$ & $(52.60)$ & $(41.50)$ \\
\hline$R^{2}$ & 0.81 & 0.90 & 0.74 \\
\hline ADF & -2.53 & -2.69 & -2.11 \\
\hline Z\&A & -4.95 & -4.43 & -2.51 \\
\hline
\end{tabular}

Notes: This table reports the results from the linear cointegration tests applied to the three interest rate series according to Engle and Granger (1987)'s two-step procedure. Empirical t-statistics are given in parenthesis. ADF and Z\&A designate respectively the empirical statistics of the Augmented Dickey-Fuller without trend and constant, and Zivot and Andrews (1992) stationary tests. 
Table 6: Johansen tests

\begin{tabular}{lrrrr}
\hline $\begin{array}{l}\text { Hypothesized number } \\
\text { of CE(s) }\end{array}$ & Eigenvalue & Trace statistics & $\mathbf{5 \%}$ critical value & Probability \\
\hline None & 0.033 & 60.15 & 42.91 & 0.00 \\
At most 1 & 0.007 & 13.69 & 25.87 & 0.68 \\
At most 2 & 0.002 & 3.40 & 12.51 & 0.82 \\
\hline
\end{tabular}

Notes: ${ }^{*}$ denotes the rejection of the null hypothesis at the $5 \%$ level. 
Table 7: VECM estimation results

\begin{tabular}{lrrr}
\hline Variables & D(YF) & D(YUK) & D(YUS) \\
\hline CointEq1 $(\times 10)$ & -0.010 & -0.004 & 0.003 \\
& {$[-4.38]$} & {$[-0.64]$} & {$[0.55]$} \\
D(YF $(-1))$ & 0.535 & 0.600 & 0.201 \\
& {$[18.6]$} & {$[6.69]$} & {$[2.62]$} \\
D(YF(-2)) & 0.172 & -0.093 & 0.238 \\
& {$[6.01]$} & {$[-1.04]$} & {$[3.12]$} \\
D(YUK $(-1))$ & 0.022 & 0.146 & -0.055 \\
& {$[2.39]$} & {$[5.10]$} & {$[-2.23]$} \\
D(YUK $(-2))$ & 0.003 & 0.023 & 0.017 \\
& {$[0.39]$} & {$[0.82]$} & {$[0.70]$} \\
D(YUS $(-1))$ & -0.001 & 0.072 & 0.499 \\
& {$[-0.12]$} & {$[2.21]$} & {$[17.8]$} \\
D(YUS $(-2))$ & 0.004 & 0.092 & 0.008 \\
& {$[0.43]$} & {$[2.81]$} & {$[0.29]$} \\
Constant $\left(\times 10^{5}\right)$ & -0.237 & -1.730 & -0.451 \\
& {$[-0.80]$} & {$[-1.88]$} & {$[-0.57]$} \\
\hline R-squared & 0.54 & 0.18 & 0.34 \\
Adj. R-squared & 0.54 & 0.17 & 0.33 \\
\hline
\end{tabular}

Notes: this table reports the estimation results from the VECM for linear adjustments of short-term interest rates. Values between brackets denote t-ratios of the estimates. 
Table 8: Nonlinear adjustment test and transition function specification

\begin{tabular}{lrrr}
\hline Delay & US & France & UK \\
\hline$p$ & 4 & 4 & 4 \\
$\hat{d}$ & 4 & 1 & 4 \\
$p$-value & $(0.00)$ & $(0.00)$ & $(0.00)$ \\
Teräsvirta (1994)'s test conclusion & ESTECM & ESTECM & ESTECM \\
\hline
\end{tabular}

Notes: $p$ is the optimal number of lags, and $\hat{d}$ refers to the optimal value for the delay parameter of the transition variable $z_{t-d}$. 
Table 9: ESTECM estimation results

\begin{tabular}{lrrr}
\hline & US & France & UK \\
\hline$p$ & 4 & 4 & 4 \\
$\hat{d}$ & 4 & 1 & 4 \\
$\hat{\gamma}$ & $8.05^{*}$ & $6.07^{*}$ & $2.78^{* *}$ \\
$c\left(\times 10^{2}\right)$ & $(2.4)$ & $(1.99)$ & $(1.74)$ \\
& $-0.07^{* *}$ & $0.20^{* *}$ & $-0.02^{*}$ \\
$\hat{\phi}_{0}\left(\times 10^{4}\right)$ & $(-1.66)$ & $(1.79)$ & $(-3.06)$ \\
$\hat{\lambda}_{1}$ & -0.13 & $-0.14^{*}$ & $-0.10^{*}$ \\
$\hat{\lambda}_{2}$ & $(-1.5)$ & $(-2.7)$ & $(-2.0)$ \\
$\hat{\phi}_{1,1}$ & $-0.05^{*}$ & $0.009^{*}$ & 0.006 \\
$\hat{\phi}_{1,2}$ & $(-4.2)$ & $(2.35)$ & $(1.44)$ \\
$\hat{\phi}_{1,3}$ & $-0.06^{*}$ & $-0.011^{*}$ & $-0.06^{*}$ \\
$\hat{\phi}_{1,4}$ & $(-4.1)^{*}$ & $(-2.71)$ & $(-3.0)$ \\
$\hat{\phi}_{2,1}$ & $0.50^{*}$ & $0.49^{*}$ & $0.15^{*}$ \\
$\hat{\phi}_{2,2}$ & $(17.9)$ & $(17.1)$ & $(5.3)$ \\
$\hat{\phi}_{3,1}$ & -0.02 & $0.08^{*}$ & 0.02 \\
\hline $\mathrm{DW}$ & $(-0.70)$ & $(2.7)$ & $(0.57)$ \\
$\mathrm{ADF}$ & $0.07^{*}$ & $0.09^{*}$ & 0.14 \\
Number of iterations & $(2.4)$ & $(3.1)$ & $(1.44)$ \\
\hline & $0.09^{*}$ & $0.11^{*}$ & $0.14^{*}$ \\
& $(3.4)$ & $(4.1)$ & $(5.0)$ \\
& $0.19^{*}$ & - & $0.06^{*}$ \\
& $(2.6)$ & & $(2.0)$ \\
& $0.28^{*}$ & - & $0.06^{* *}$ \\
& $(3.8)$ & & $(1.85)$ \\
& $-0.08^{*}$ & 0.02 & $0.51^{*}$ \\
$(-3.4)$ & $(2.5)$ & $(7.0)$ \\
\hline & 2.02 & 2.01 & 2.0 \\
& 19 & -26.42 & -26.56 \\
& 26 & 12 \\
\hline
\end{tabular}

Notes: The values in parenthesis are the t-ratios. DW, ADF and ARCH are the empirical statistics of the Durbin Watson, ADF and ARCH tests. $\left(^{*}\right)$ and $\left(^{* *}\right)$ indicate that estimated coefficients are significant at the $5 \%$ and $10 \%$ respectively. 
Figure 1: Time-variations in 3-month interest rates

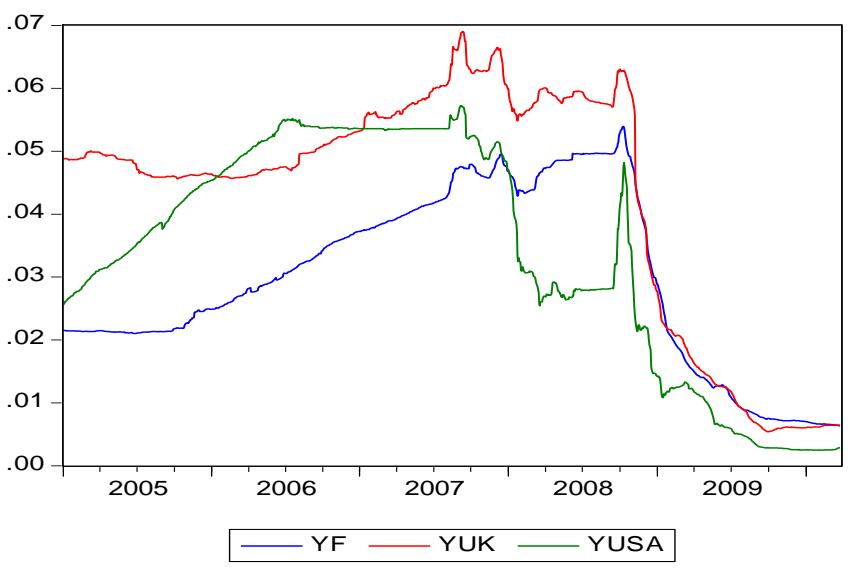

Note: This figure depicts the dynamics of the three interest rates over the period from December 31, 2004 to March 30, 2010. They refer to the daily 3-month interest rates of France (YF), the Unites States (YUS), and the United Kingdom (YUK). 
Figure 2. Estimated transition functions of the ESTECMs for the UK, US and French interest rates
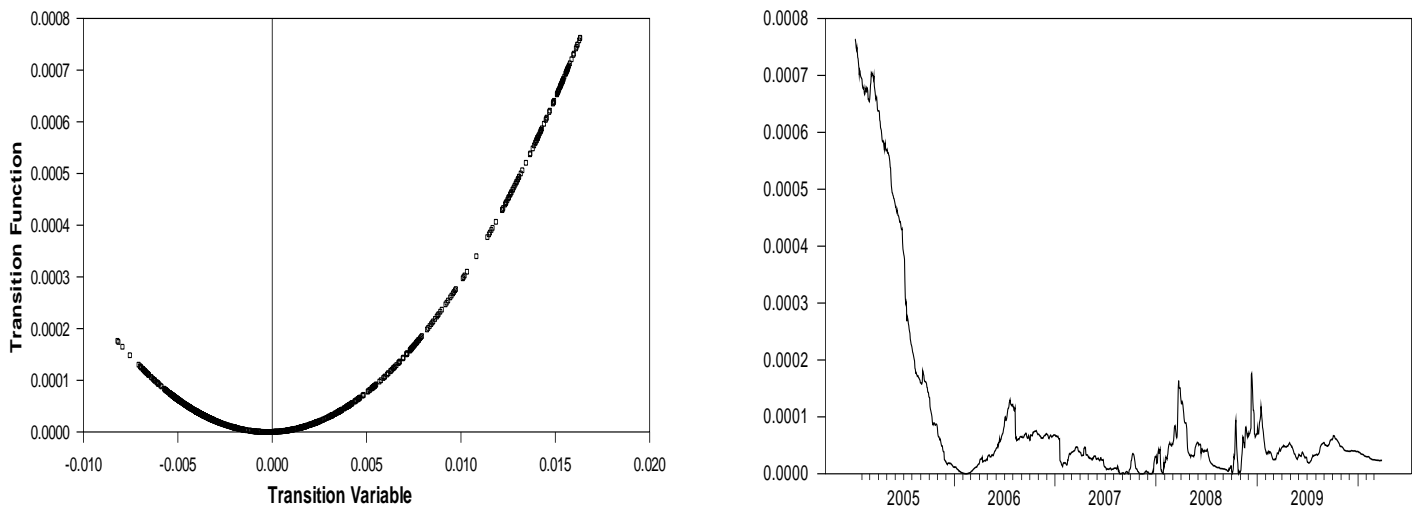

A) Transition function for the UK

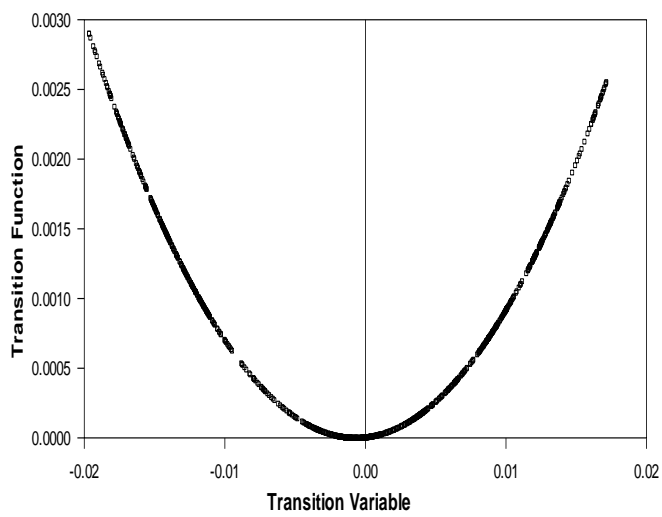

B) Intertemporal transition function for the UK

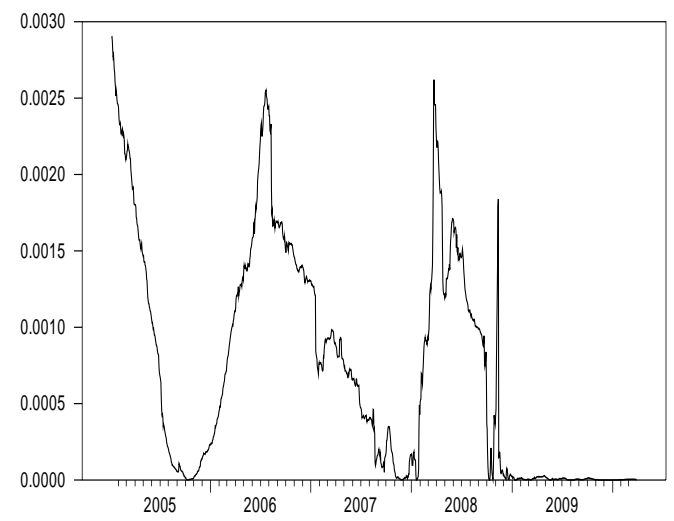

C) Transition function for the US

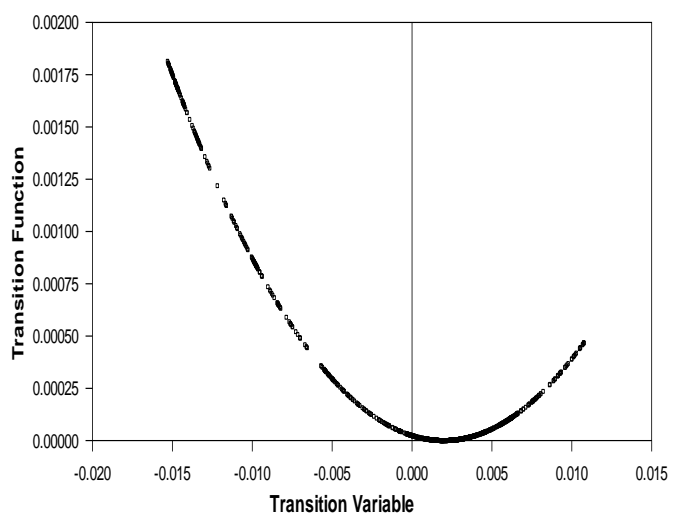

E) Transition function for France

D) Intertemporal transition function for the US

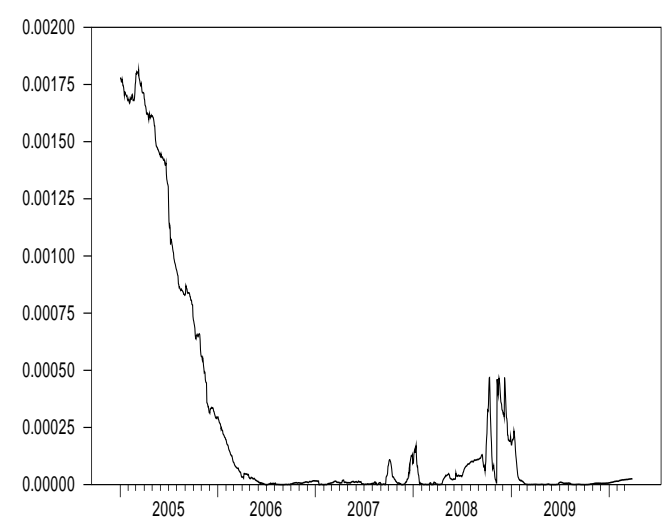

F) Intertemporal transition function for France 